\title{
Lapa Mine - ground control practices in extreme squeezing ground
}

\author{
F. Mercier-Langevin Agnico-Eagle Mines Ltd., Canada \\ D. Wilson Agnico-Eagle Mines Ltd., Canada
}

\begin{abstract}
Many underground hard rock mines have to deal with various degrees of squeezing in underground tunnels. Depending on the severity of the phenomenon, considerable investments either in rock reinforcement and support can be necessary. In worst cases, time-consuming and possibly hazardous scaling and rehabilitation operations can be required to keep drifts serviceable. Therefore, a proper understanding of the rock mass, its response to excavation and the mechanisms involved is paramount to the design of cost-effective ground support systems in squeezing ground.

The Lapa gold mine located in northwestern Quebec operates in such challenging ground conditions. Using field observations and data from the Hard Rock Squeezing Ground Index (Mercier-Langevin and Hadjigeorgiou, 2011), a plausible failure mechanism is proposed. The resulting ground control strategy is presented.
\end{abstract}

\section{$1 \quad$ Introduction}

Squeezing of rock has been defined as the time dependent large deformation which occurs around tunnels caused by stress (Barla, 1995). Hoek (2001) suggests that such deformation can be considered 'extreme' when strain, calculated as the ratio of deformation on a given wall over drift radius, exceeds $10 \%$. Drift deformations at Lapa routinely exceed this value. In some cases drift closure exceed 2 metres, resulting in strain values in excess of $40 \%$. Using field observations and data from the Hard Rock Squeezing Ground Index (Mercier-Langevin and Hadjigeorgiou, 2011), a plausible failure mechanism is proposed, and the resulting ground control strategy is presented.

In the author's experience, failing to appreciate the challenges associated with this phenomenon or the magnitude of the deformations early on can result in serious operational problems, ranging from hindered production to safety issues.

\section{$2 \quad$ Lapa Mine}

The Lapa gold mine is Agnico-Eagle's highest grade mine (Agnico-Eagle Mines Ltd, 2012). The property straddles the Cadillac Break in the Abitibi Region of Quebec, approximately $500 \mathrm{~km}$ to the north-west of Montreal (Figure 1). The mine has been in operation since 2009. It is accessed via a 1,369 m deep, $4.9 \mathrm{~m}$ diameter shaft (Figure 2).

The mine currently produces around 100,000 ounces of gold per year, or about $10 \%$ of Agnico-Eagle's total current yearly production. As of 31 December 2011, proven and probable reserves were 2.4 million $\mathrm{t}$ grading $6.5 \mathrm{~g} / \mathrm{t}$ (fully diluted) for 0.5 million ounces of gold. Known reserves project the mine life to the end of 2015 with exploration ongoing (Agnico-Eagle Mines Ltd, 2012). 


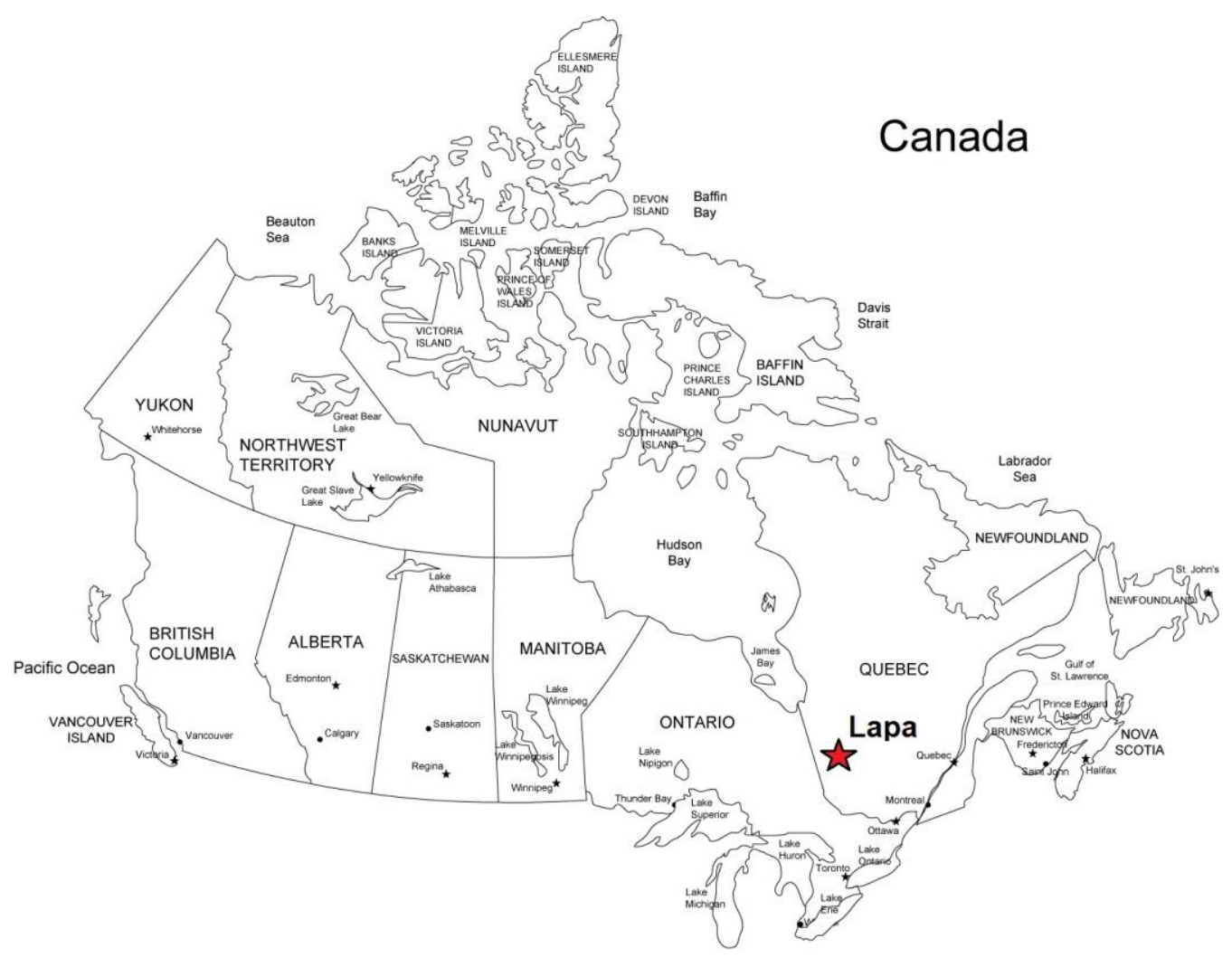

Figure 1 Location of Lapa

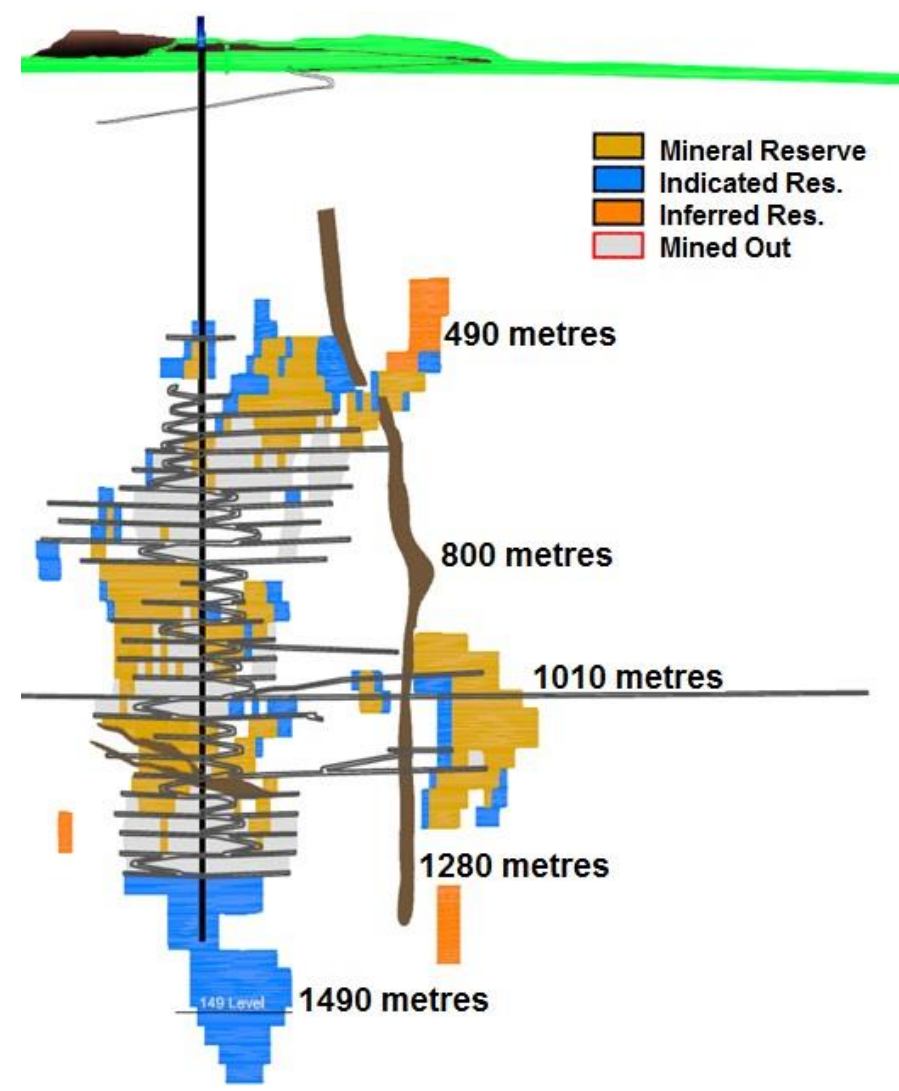

Figure 2 Longitudinal view of the mine (looking north) 


\subsection{Geological setting}

The Lapa deposit is a disseminated gold deposit hosted by deformed and silicified volcanic and sedimentary rocks (minor disseminated pyrite, arsenopyrite and stibnite occur along with visible gold). The deposit is roughly east-west trending and vertically dipping. It begins at a depth of approximately $400 \mathrm{~m}$ below surface and can be traced to a depth of 1,600 m and over $400 \mathrm{~m}$ horizontally. The Lapa deposit is made up of at least five narrow sub-parallel and adjacent lenses averaging less than $5 \mathrm{~m}$ in thickness. Three of these lenses are currently in production; the Contact, Footwall and Middle lenses (Figure 3). The Contact zone contains approximately $84 \%$ of the current known reserves (Laing, 2012).

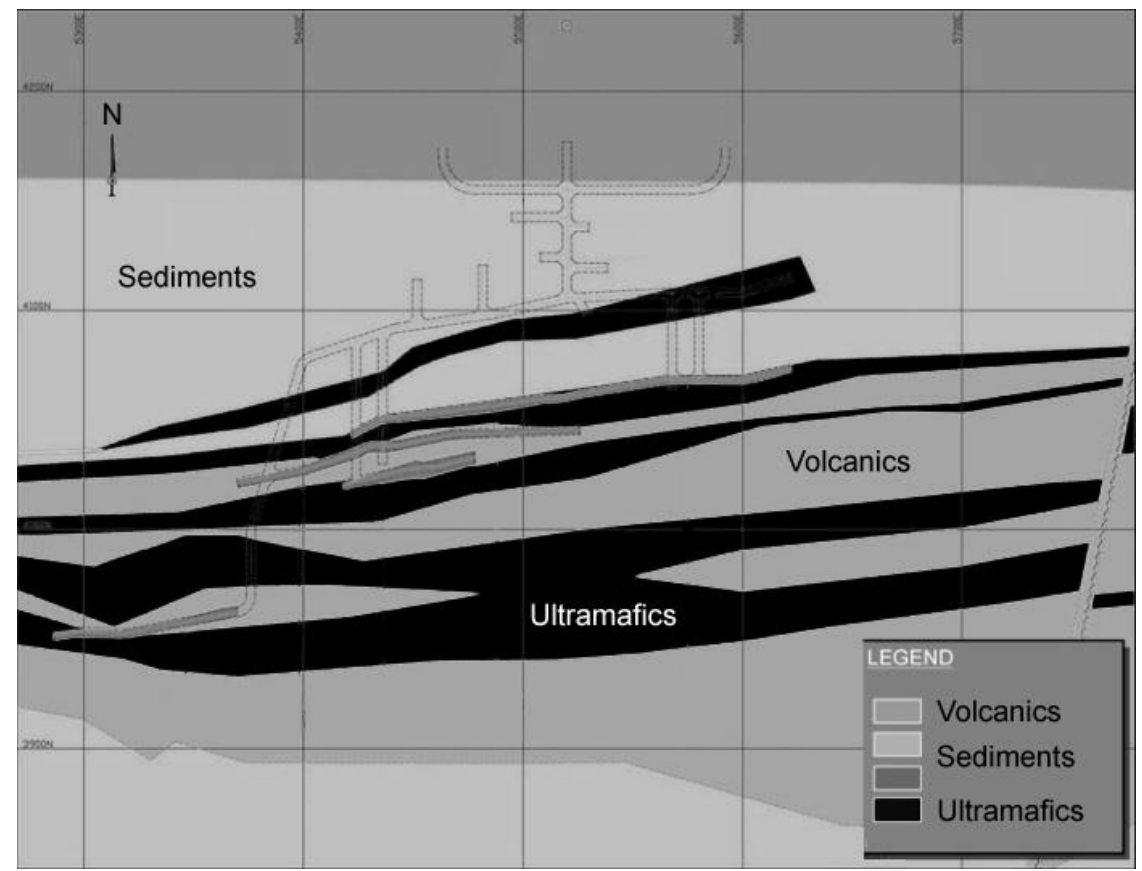

Figure 3 Plan view of lithological sequence

There are three distinct geological domains at the mine pertaining to rock mechanics. Very weak schist zones further referred to as ultramafics, and two significantly more competent units, sediments to the north and volcanics to the south. The ore is typically found at the contact of the sediments and the ultramafics, hence the name 'Contact lens'. These three units are foliated to varying degrees, with foliation planes primarily oriented sub-parallel to the orebody.

The weakness of the ultramafics is compounded by two factors. The foliation spacing is typically smaller in this unit and the joints are slickensided from talc-chlorite alteration. Rock properties of interest to this paper will be further discussed in Section 3.1.

No stress measurements have been done at Lapa. The equations used for in-situ stress calculations are the same as those used at LaRonde, which is situated $11 \mathrm{~km}$ to the west of the Lapa Mine. Following this assumption, the major principal stress is oriented roughly north-south and is 1.6 times the vertical stress. Field observations seem to support this assumption even though the convoluted geological history of the Lapa orebody results in important variations in certain areas of the mine.

\subsection{Mining method}

The primary mining method used at Lapa is longitudinal open stoping with cemented backfill (Figure 4). Sublevels are developed at $30 \mathrm{~m}$ intervals and the ore is removed between the sublevels using the long hole blasting technique in a longitudinal retreat configuration. Typical stope size is $12 \mathrm{~m}$ wide by $30 \mathrm{~m}$ high (floor to floor) with a thickness varying between 3 and $5 \mathrm{~m}$. When the width of the ore exceeds $6 \mathrm{~m}$, or when two or three lenses are close enough to mine together, primary-secondary transverse stoping is used. 

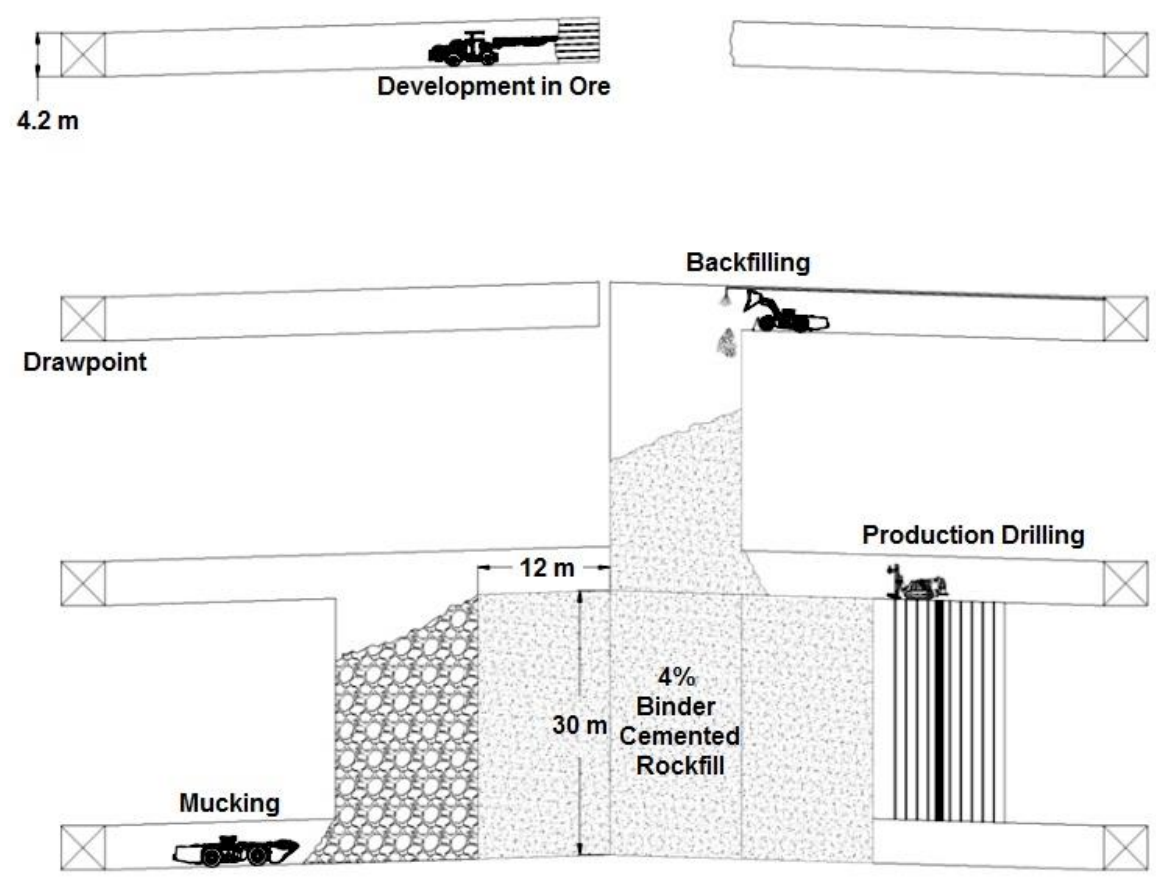

Figure 4 Longitudinal retreat open stoping

Although the longitudinal retreat method is very well suited to narrow vein mining from an economic standpoint, it also has significant adverse effects from a geomechanical point of view. First of all, this method concentrates stresses in ore drifts which are developed at a very shallow angle to foliation, both conditions conducive to squeezing (Mercier-Langevin, 2005; Potvin and Hadjigeorgiou, 2008; MercierLangevin and Turcotte, 2007; Mercier-Langevin and Hadjigeorgiou, 2011). Under these conditions, keeping drifts open for the entire life of an extraction panel can be challenging. This is especially pertinent considering that in the later stages of extraction of a panel a diminishing pillar is created in which stresses can be very high.

Conversely, when the transverse mining method is used, development is realised perpendicular to the ore zone and drifts are utilised for very short periods of time. Negligible squeezing occurs in the drawpoints used for transverse stoping.

\section{$3 \quad$ Squeezing at Lapa}

Figures 5 to 7 show typical drift deformation in squeezing ground. All these pictures were taken in drifts running at a very shallow angle to foliation. Deformations in the relatively competent sediments or volcanics are easily managed, whereas ultramafics display massive deformation requiring time-consuming and often hazardous rehabilitation operations which often interfere with production.

In the case of Figure 5, deformation is concentrated on the South wall in ultramafics, with the apex of deformation occurring in the lower part. Strain on this wall is in the order of 15 to $20 \%$. The back and floor, composed of sediments show little to no degradation. Degradation of the North wall is barely visible at less than $2.5 \%$ strain. 

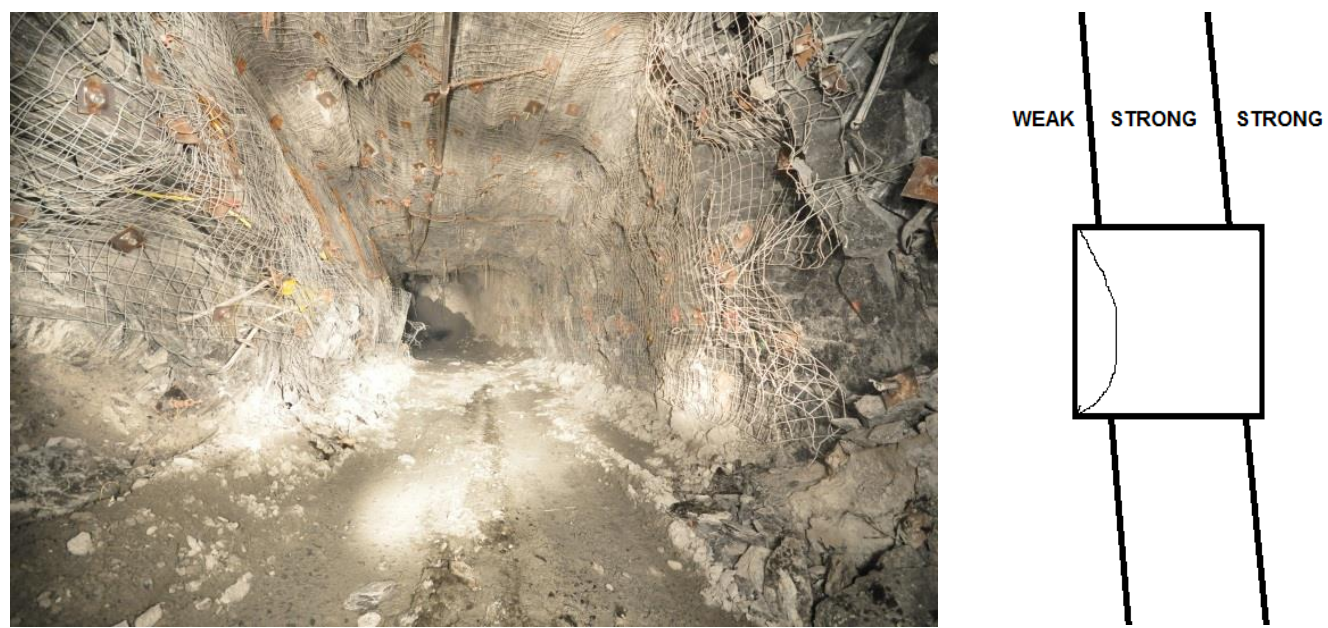

\section{Figure 5 Deformation in a haulage drift with South wall (left) in ultramafics}

Figure 6 shows an example of deformation that can be observed when ultramafics extend into the back and floor of a drift. In this situation, deformation occurs not only in the ultramafic wall but carries into the floor and back. This is shown by floor heaving noticeably along the South wall as evidenced by the noticeable tilt of the tractor. The back is coming down, also along the South wall but it is mostly hidden by the ventilation tubing. In this example, strain in the South wall is estimated at $15 \%$ even though it's in the early stages of deformation. Strain along the back and floor vary from almost nothing along the competent North wall to about $10 \%$ along the South wall. Even though the picture was taken shortly after development of the drift, deformation in the South wall is already as pronounced as in Figure 5; implying that floor and back closure exacerbates wall deformations.
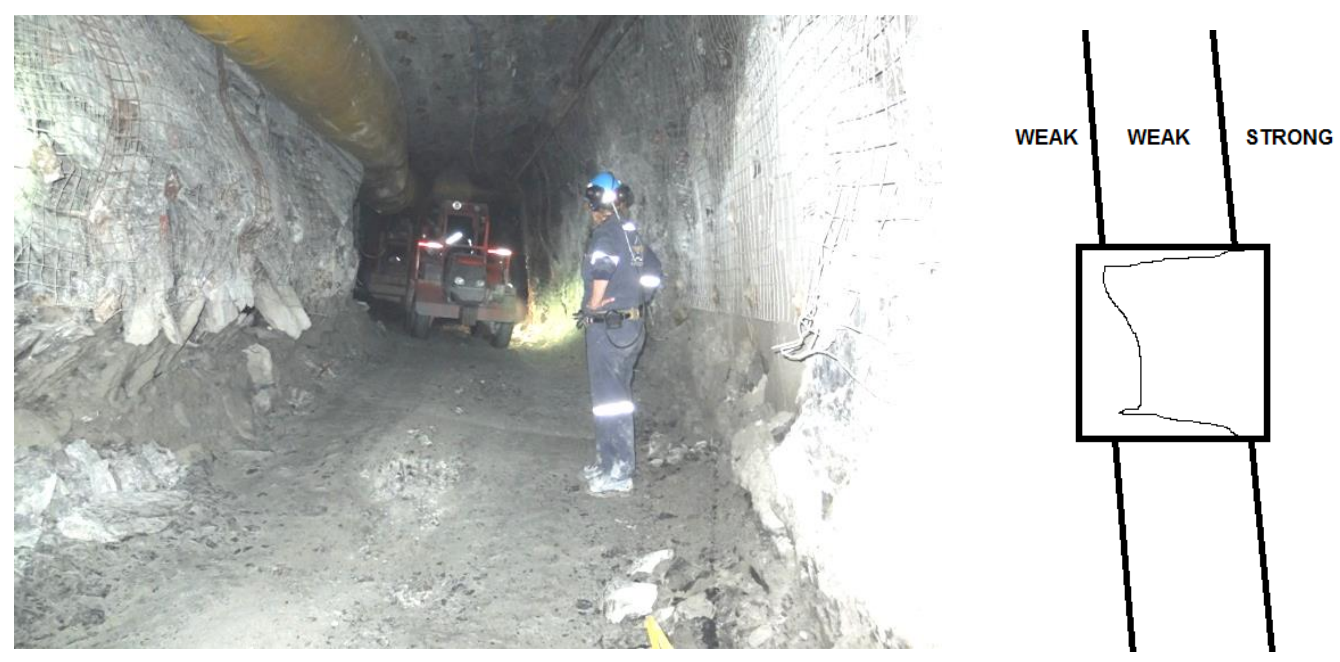

Figure 6 Early stage deformation in an ore drift where only the North wall (right) is in competent sediments

Figure 7 shows the worst case scenario, in which the drift is located entirely in ultramafics. Again, deformation in walls is concentrated on the lower part of the South wall and the upper part of the North wall. Both of these walls exhibit as much as $40 \%$ strain at the apex. This is visible on the North wall only as excess material in the South wall has been purged. 

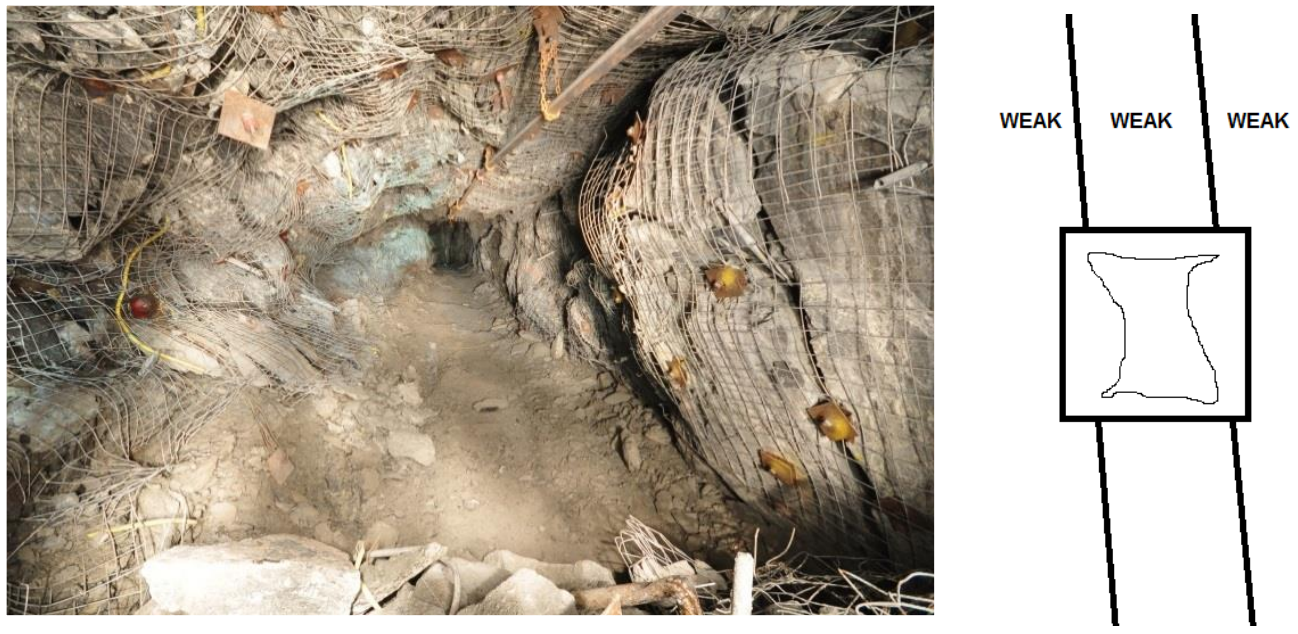

Figure 7 Late stage deformation in an ore drift entirely in ultramafics (note that the South wall to the left has been purged once)

Figure 8 shows how dramatically the squeezing potential of ultramafics varies according to the angle at which the drift has been developed with regards to foliation. To the left is a haulage drift, developed almost parallel to foliation in ultramafics. To the right is a drawpoint developed perpendicular to that haulage drift and hence to the foliation. In the haulage drift to the left, the walls have buckled, but more importantly, the floor has heaved and the back has come down significantly, whereas in the drawpoint, a perfect square shape remains, even though development was done at the same time and under similar stress conditions.

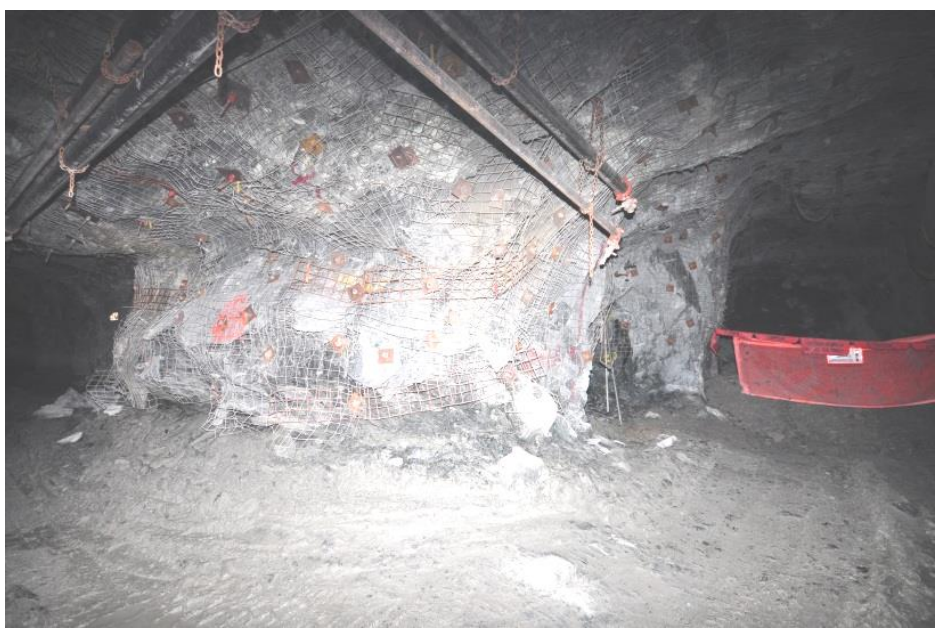

Figure 8 Drawpoint (right - perpendicular to foliation) running perpendicular to the haulage drift (left - parallel to foliation)

In summary, the following key observations can be made from the preceding examples:

- Without ultramafics, convergence is insignificant at Lapa.

- Only drifts developed at a shallow angle to foliation exhibit significant degrees of convergence. In all cases, buckling of the foliation planes appears to be the driving mechanism.

- Wall convergence seems to be exacerbated by back and floor failure, and vice-versa.

Finally, two observations made in the field that have not been shown in the above examples but are relevant:

- Removal of failed material in the walls does not promote other 'episodes' of closure. 
- Most of the deformation occurs first in the walls. Deformation in the walls slows down later in the process while deformation accelerates in the back and floor.

\subsection{Hard rock squeezing ground index}

At LaRonde, where the matrix was developed, the influence of drift orientation with regards to foliation was considered the most important factor affecting squeezing severity. It was observed that as the angle of interception $(\psi)$ increases, squeezing becomes almost purely stress-driven, and foliation spacing has little to no effect on the squeezing potential of the rock. These observations were used to develop a series of prediction matrices (Figure 9).

$0^{\circ}<\psi<25^{\circ}$

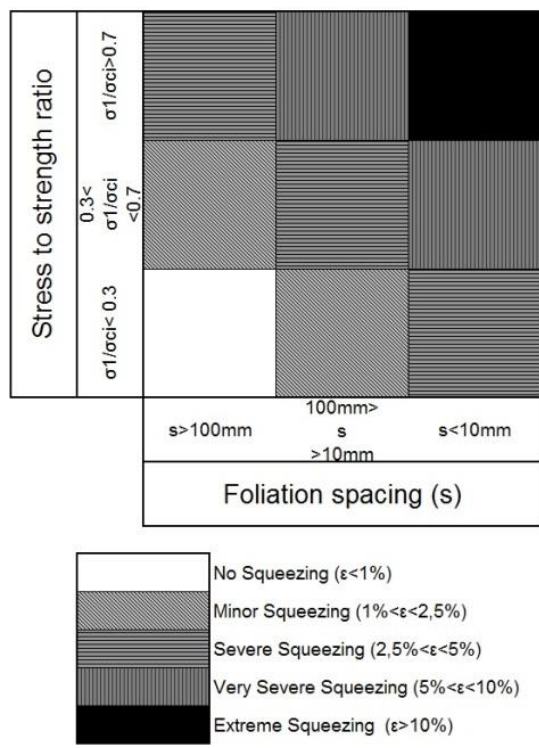

$25^{\circ}<\psi<40^{\circ}$

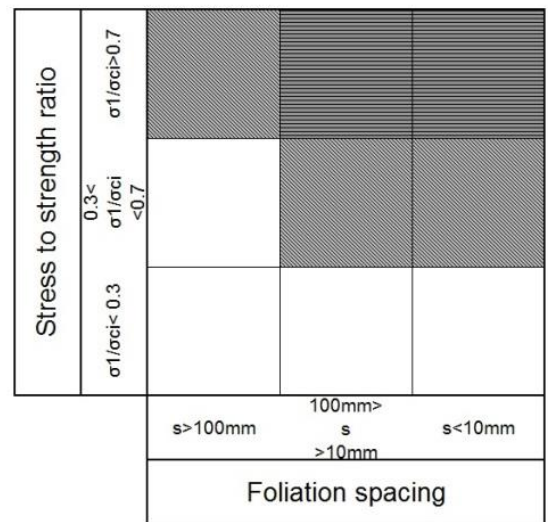

$\underline{40^{\circ}<\psi<90^{\circ}}$

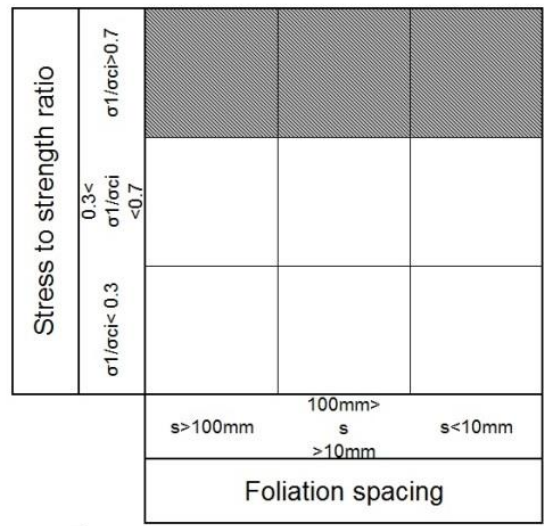

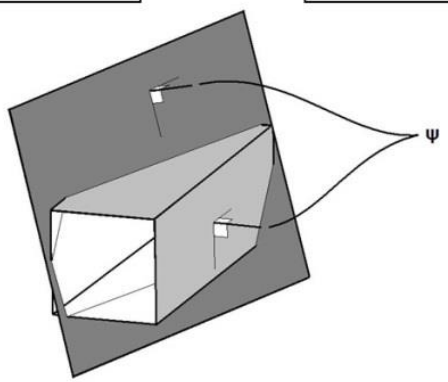

Figure 9 Different squeezing matrices for varying angles of interception (after Mercier-Langevin and Hadjigeorgiou, 2011)

For the purposes of squeezing prediction, the three distinct geological domains present at Lapa were treated separately. The input parameters used for each domain can be found in Table 1 . The resulting predictions by the squeezing ground matrix can be found in Figure 10.

Table 1 Input parameters

\begin{tabular}{cccccc}
\hline Unit & UCS & \multicolumn{2}{c}{ Stress (MPa) } & \multicolumn{2}{c}{ Foliation Spacing (mm) } \\
& (MPa) & Best & Worst & Best & Worst \\
\hline Sediments & $80-90$ & 21 & 55 & 200 & 10 \\
Ultramafics & $20-25$ & 21 & 55 & 50 & 1 \\
Volcanics & $50-60$ & 21 & 55 & 200 & 50 \\
\hline
\end{tabular}


$\underline{0^{\circ}<\psi<25^{\circ}}$

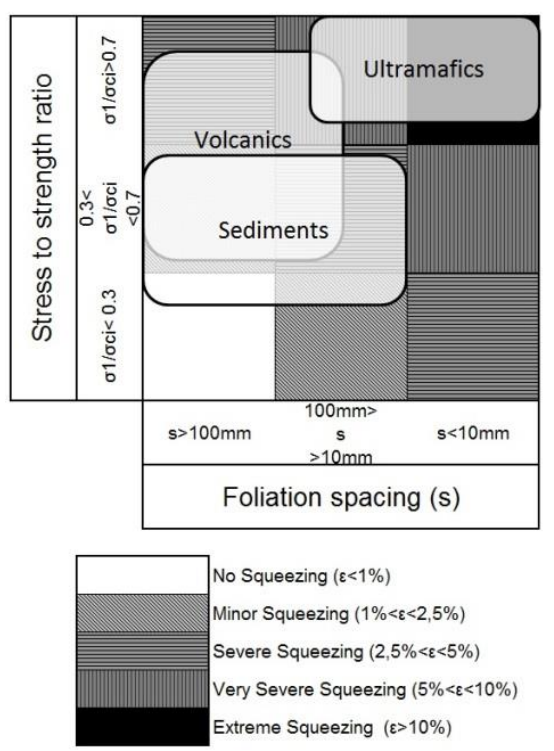

$\underline{25^{\circ}<\psi<40^{\circ}}$

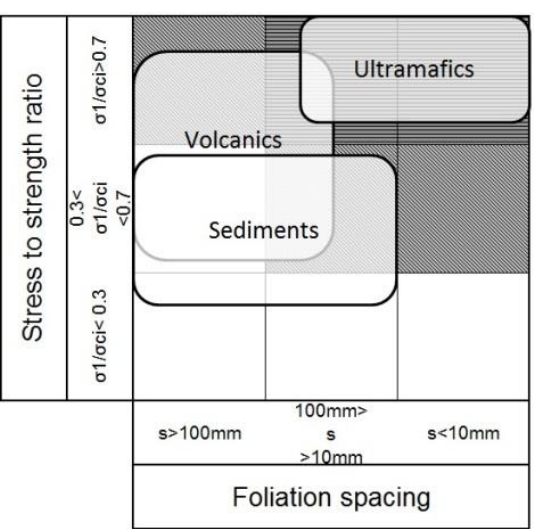

$\underline{40^{\circ}<\psi<90^{\circ}}$

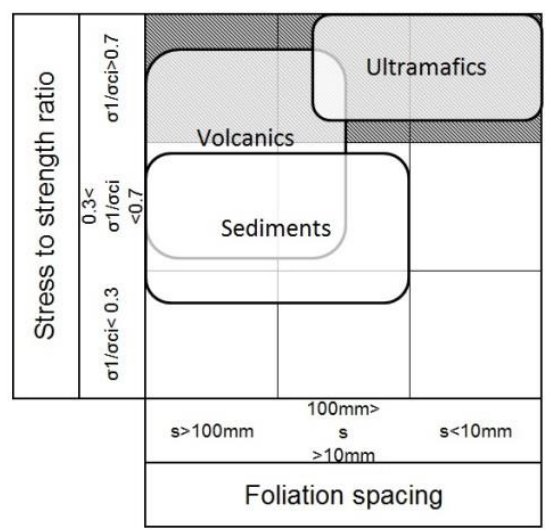

Figure 10 Squeezing predictions for Lapa

Predictions by the squeezing ground matrix for the competent volcanic and sedimentary rock concur with experience at Lapa. In drifts that are perpendicular to foliation, strain never exceeds $2.5 \%$. In haulage drifts that are parallel to foliation, strain is typically below $2.5 \%$ and only exceeds $5 \%$ in rare cases in deeper levels of the mine and where the rock is locally altered and/or highly foliated.

Predictions by the squeezing ground matrix for ultramafic rock at Lapa are in the right categories. When drifts are developed perpendicular to the ultramafic rock for the transverse mining method, very little strain occurs. This is in agreement with the prediction of less than $2.5 \%$ strain. However, Figures 5 to 7 were all examples of squeezing in drifts running sub-parallel to foliation in ultramafics. Strain exceeded $5 \%$ in all of the examples and reached levels as high as $40 \%$. The squeezing ground matrix correctly places these conditions in the extreme category but fails to capture the high levels of strain.

\section{$4 \quad$ Ground support in drifts}

A proper understanding of the rock mass, its response to excavation and the mechanisms involved is paramount to the design of effective ground support systems. The following sections provide an interpretation of the failure mechanism in squeezing ground and how ground support practices have evolved to mitigate its effects.

\subsection{Interpretation of the mechanism}

For the sake of simplicity, the following interpretation of the mechanism is the worst case scenario; it takes place in a drift where both walls and back are in foliated ultramafics (similar to Figure 7). Based on experience at Lapa and LaRonde, the primary driving factor for squeezing in hard rock is the presence of foliation running at a shallow angle to the drift. There are three reasons why this configuration is conducive to squeezing.

The first is that weak foliated rock is particularly sensitive to buckling failure. Regardless of the orientation of stresses or of foliation, stress redistribution around an excavation always results in axial loading of foliation planes. These same stresses cause rock elements adjacent to these foliation planes to deform; contraction in the orientation of the major principal stress or along foliation, and dilation in the direction of the minor principal stress or towards the opening. This dilation induces deflection of the rock layers, significantly lowering the critical axial load necessary for buckling to occur (Figure 11). As buckling 
progresses, this process migrates further and further into the rock mass, inducing shear on foliation planes. The effects of this process on reinforcement elements were explored by Simser et al. (2006).

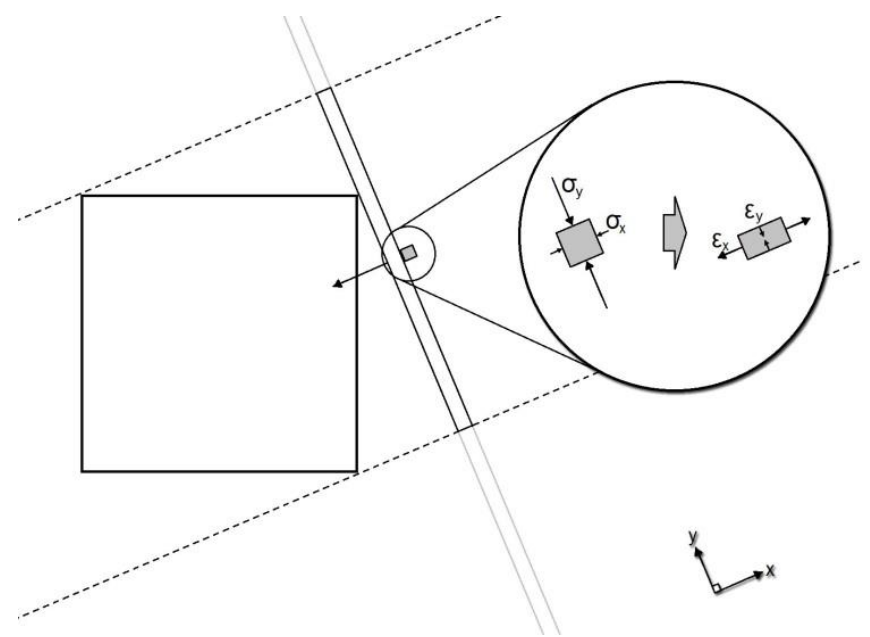

Figure 11 Initiation of buckling failure in foliated rock

The second reason is that foliated rock will preferentially bulk orthogonal to foliation planes. This is due to the fact that the number of joints that will open up when the rock fails is higher orthogonal to foliation as illustrated in Figure 12. In this simple example, it is assumed that each joint in an intact $1 \times 1 \mathrm{~m}$ block of rock opens up by $1 \mathrm{~cm}$ due to joint roughness after failure. As a result, the direction in which the highest number of joints are present is the one in which the most bulking will occur.
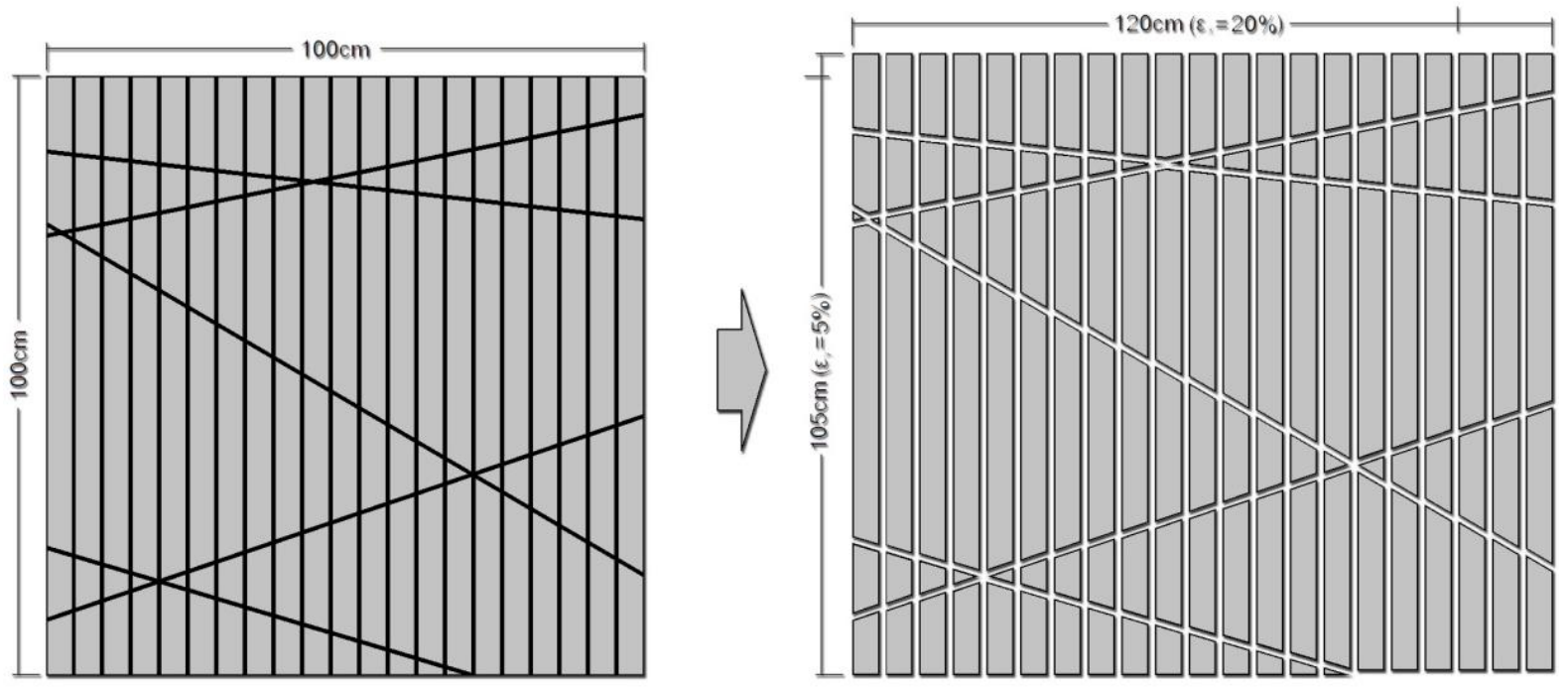

Figure 12 Anisotropic rock bulking following failure of foliated rock

The third reason is that once buckling has been initiated, the buckled rock provides minimal confinement to the floor and back of the excavation as the only force resisting the movement is from friction between foliation planes. This is illustrated in Figure 13. This buckling corridor results in a much larger relaxed zone and the excavation having a much larger effective span. At both Lapa and LaRonde, the buckling corridor has been observed to extend as much as 6 to $7 \mathrm{~m}$ into the rock mass (Mercier-Langevin and Turcotte, 2007), making the effective span of these excavations approximately four times the drift width. This very large relaxed zone fails under the concentrated horizontal stresses and bulks in a fashion similar to what was proposed by Sandy et al. (2007), but on a much larger scale. This is in agreement with the fact that deformation seems to occur in two distinct stages. Early in the process, wall closure is very fast while the back and floor remain mostly stable. Later in the process, wall closure slows down, but back and floor convergence accelerates. Figure 14 shows field evidence of this process exposed by benching of the floor 
and purging the South wall. In this particular example, original drift dimensions were 4.2 by $4.2 \mathrm{~m}$. After squeezing and prior to re-excavation, dimensions were down to approximately 2.8 by $2.8 \mathrm{~m}$. North wall deformation was minimal in competent sediments.

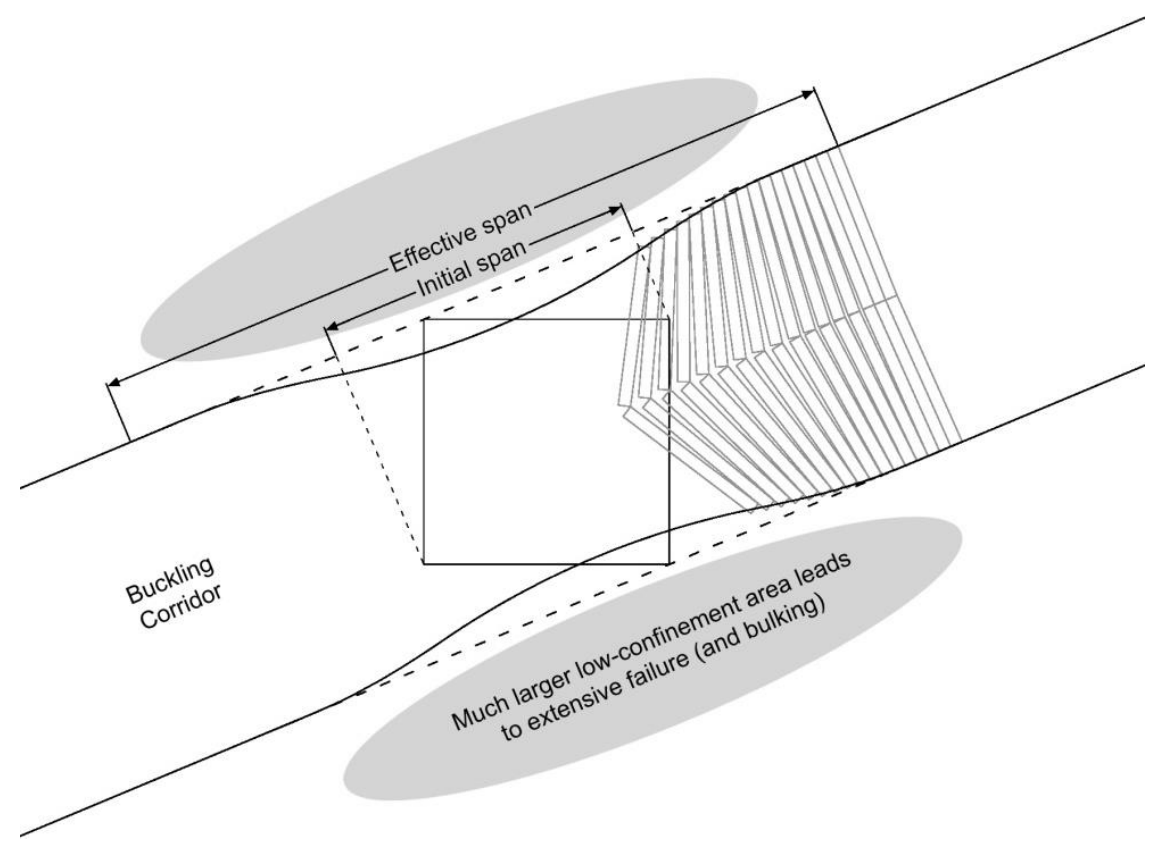

Figure 13 Loss of confinement in the back and floor following buckling of sidewalls

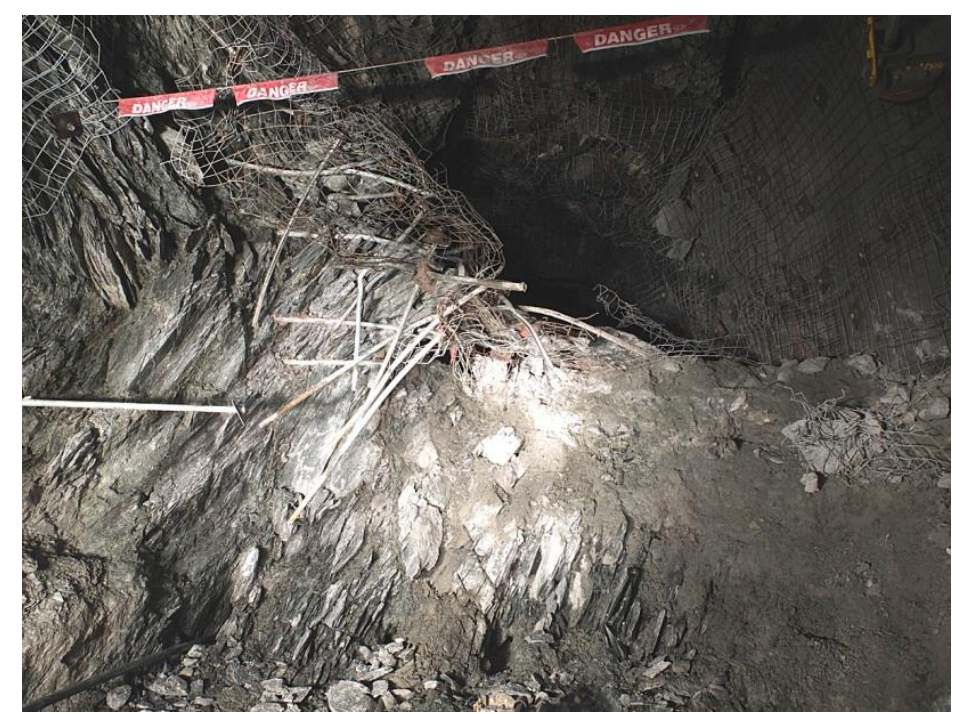

Figure 14 Drift being re-excavated

\subsection{Ground control practices}

As was made evident by the preceding sections, ground support practices in drifts at Lapa are highly dependent on the presence of ultramafics in or near the drift. Figure 15 illustrates the selection process used to define which support standard is used for any given excavation. 


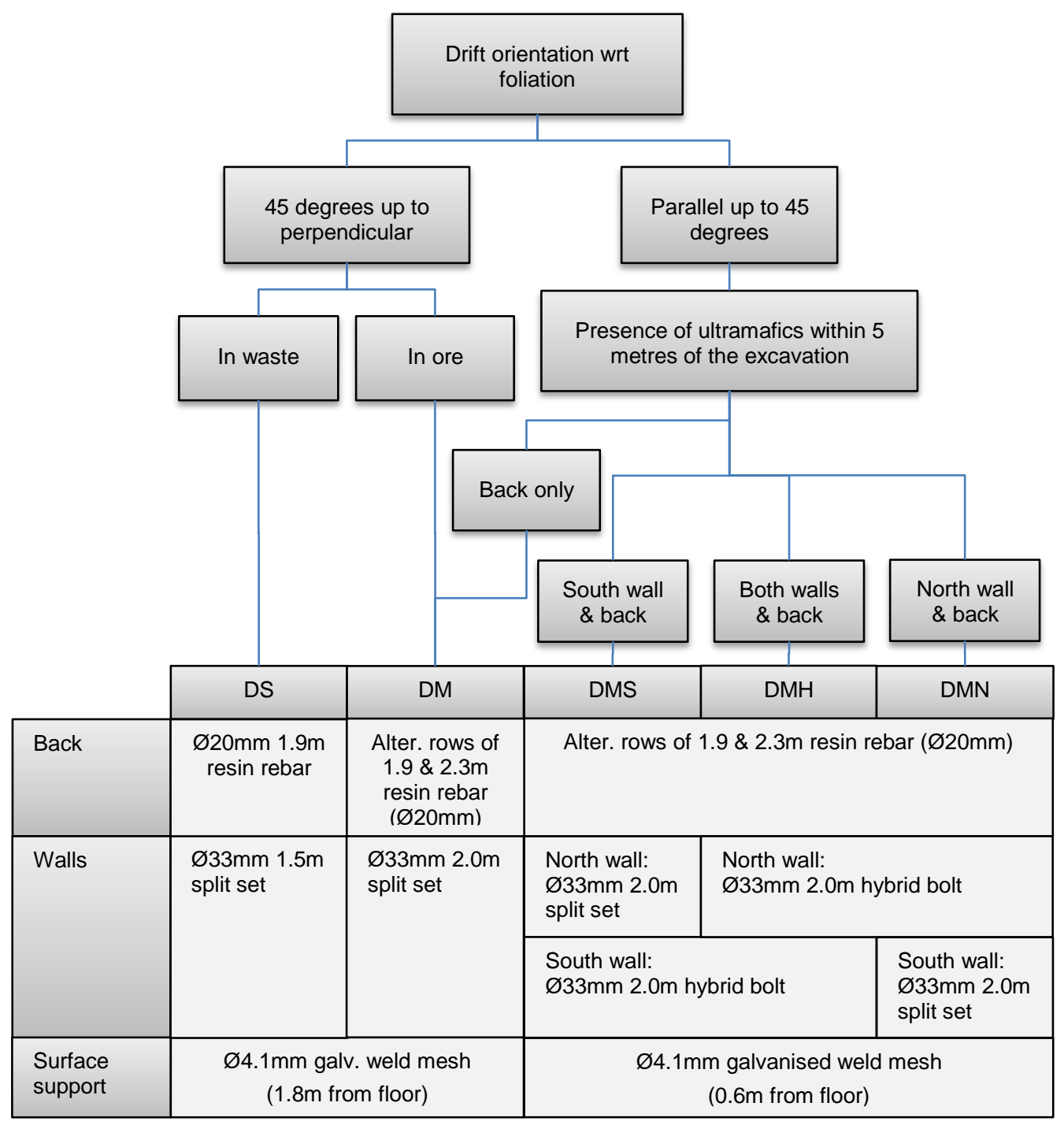

Figure 15 Selection process for ground support systems at Lapa

DS and DM are used for non-squeezing conditions. The only variation between them is that longer support is used in the back and walls in ore (DM) because these drifts are typically subjected to higher stresses than drifts in waste (haulage drifts).

DMS, DMH and DMN are used in drifts where conditions conducive to squeezing are found. In those, longer support is used in the back. Likewise, longer support is used in the walls, and split set bolts are upgraded to higher capacity hybrid bolts in the wall(s) likely to squeeze. The hybrid bolt was introduced at Lapa following its successful application at LaRonde in squeezing ground conditions. It is comprised of a $1.8 \mathrm{~m}$ forged head rebar inserted into a $2.0 \mathrm{~m}$ split set. The advantages of the hybrid bolt over other yielding tendons in squeezing ground were described in detail by Mercier-Langevin and Turcotte (2007) and Turcotte (2010). Screen surface support is brought within $0.6 \mathrm{~m}$ from the floor in all three standards in order to prevent unravelling of the lower walls.

Additional notes on bolting standards:

- All bolts are installed on a staggered pattern, with an effective spacing of $0.9 \mathrm{~m}$.

- In spans exceeding $6.5 \mathrm{~m}$ such as in intersections, longer bolts than those listed above are used as primary support. $2.9 \mathrm{~m}$ rebar or $3.0 \mathrm{~m}$ inflatable bolts are installed in alternating rows with standard length rebars.

- If the height of a drift exceeds $5 \mathrm{~m}$, the length of the wall support is increased. 
- The use of push plates (sometimes referred to as friction plates or SAAB plates) is not permitted in drifts in ultramafics due to their low capacity.

Cable bolting is also used as secondary support. In the competent sedimentary waste rock, cable bolts are only installed in the back of intersections with large spans and in drifts that intersect non-mineralised ultramafic bands. In ore drifts, cable bolts are installed systematically. Similar to the hybrid bolts, the use of cable bolts is targeted on the walls that exhibit conditions prone to squeezing. Cable bolts are installed in conjunction with high capacity $\varnothing 8.3 \mathrm{~mm}$ mesh straps. This helps prevent plates from punching through screen by strengthening the link between surface support and the stiffer cables. In the back, $8 \mathrm{~m}$ cable bolts are used, whereas $6.4 \mathrm{~m}$ long cable bolts are used in the walls, both on a spacing of $2 \mathrm{~m}$.

The installation of cable bolts is willingly delayed in time, so that the drift is allowed to deform. Experience has shown that it is preferable to install the stiffer cables later in the deformation process; cable bolts installed too early are either loaded to failure very quickly or they literally sink into the rock mass and break the screen, losing their connection to the surface support.

It was found that using shotcrete in squeezing conditions can present a short-term gain by preventing unravelling of the rock mass while bolting operations are taking place. However, as deformation starts the very stiff shotcrete quickly degrades and spalls, to the point of becoming an additional hazard that requires intervention such as scaling or screening to fix. Therefore, shotcrete use as a part of the primary support is kept to a minimum.

As is the case in burst prone ground, a support system in squeezing ground is only as strong as its weakest link (Simser, 2007). Over time, it has become apparent that the weakest link in the support system at Lapa is the connection between the tendons and the surface support. Consequently, a lot of effort is being put into matching the stiffness of the various elements in order to mobilise them as a system.

In drifts where clearance becomes insufficient for production equipment, the mine resorts to purging. The excess broken material is removed with a 6-yard scooptram and support in the affected section is restored to specifications. This operation is carried out in sections of a maximum length of $5 \mathrm{~m}$ and under supervision of ground control personnel. Longer support in the back also needs to be present before this operation is carried out as it is often difficult to control the amount of broken material that falls off, and the final span of the excavation can be larger than anticipated.

Overall, the described ground control practices are very effective. They enable most drifts to sustain as much as 40 to $50 \%$ strain with minimal maintenance required. Only when clearance becomes insufficient is a major intervention needed.

\section{Conclusions}

Observations in squeezing ground at Lapa were provided, and data from Lapa was input into the Hard Rock Squeezing Ground Index. Field observations at Lapa validated the key factors identified by the Index. Foliation is critical to the onset of squeezing conditions. Furthermore, this foliation needs to be exposed by development at a shallow angle. In these conditions, buckling is the identified failure mechanism leading to squeezing. Finally, squeezing potential increases with stress.

Strain predictions for sediments and volcanics were excellent. However, although drift behaviour in ultramafics was successfully identified as 'Extreme Squeezing', the actual strain level experienced in the field (upwards of $40 \%$ in some areas) was not captured by the squeezing ground matrix, which predicted values in the range of $10 \%$. Mercier-Langevin and Hadjigeorgiou (2011) tentatively set the lower bounds for foliation spacing and UCS values whereby the matrices become questionable at approximately $15 \mathrm{MPa}$ for UCS. Experience in ultramafics at Lapa suggests that this lower bound for UCS should be raised to at least 25-30 MPa.

Dobereiner and de Freitas (1986) postulated that rocks with a UCS below about 20 MPa do not dilate when sheared whereas stronger rocks tend to bulk. The ultramafics at Lapa straddle this limit. It is surmised that 
ultramafics might combine the two failure modes as a result of relatively minor variations in alteration and foliation spacing. While most of the rock fails and bulks, a proportion of it flows plastically under load, weakening the rock mass as a whole by lubricating the process. This plastic flow component is not the driving mechanism per se, but it increases the magnitude of deformations; by increasing the size of the failure halo around the excavation it enables more rock to fail and bulk.

Even though the Hard Rock Squeezing Index was developed as a preliminary indicator of the squeezing potential of a rock mass, experience at Lapa suggests that it can also be used as a guide for ground support practices. It provides operators with some valuable insight into the key factors affecting squeezing in drifts and how to manage this phenomenon.

\section{Acknowledgement}

The authors thank Agnico-Eagle Mines Ltd for permission to publish.

\section{References}

Agnico-Eagle Mines Ltd (2012) Agnico-Eagle Reports Fourth Quarter and Full Year 2012 Results; Record Annual Production and Operating Cash Flows; Provides Three Year Production Guidance and Reserve and Resource Update, Agnico-Eagle Mines Limited, Toronto, viewed 13 February 2013, http://ir.agnicoeagle.com/English/investor-relations/news-releases/newsrelease-details/2013/-CORRECTED-COPY-from-CNW---Agnico-Eagle-Reports-Fourth-Quarter-and-Full-Year-2012-ResultsRecord-Annual-Production-and-Operating-Cash-Flows-Provides-Three-Year-Production-Guidance-and-Reserve-andResource-Update-/default.aspx.

Barla, G. (1995) Squeezing rocks in tunnels, ISRM News Journal, International Society for Rock Mechanics, Portugal, Vol. 2, No. 3/4, pp. 44-49.

Dobereiner, L. and De Freitas, M.H. (1986) Geotechnical properties of weak sandstones, Géotechnique, Vol. 36, No. 1, 1986, pp. 79-94.

Hoek, E. (2001) Big tunnels in bad rock, ASCE Journal of Geotechnical and Geoenvironmental Engineering, Vol. 127, No. 9, pp. 726-740.

Laing, R.G. (2012) Agnico-Eagle Mines Ltd - Annual report pursuant to section 13 or 15(d) of the Securities Exchange Act of 1934 for the fiscal year ended December 31 2012, United States Securities and Exchange Commission.

Mercier-Langevin, F. and Wilson, D. (2013) Lapa mine - ground control practices in extreme squeezing ground, in Proceedings Seventh International Symposium on Ground Support in Mining and Underground Construction, B. Brady and Y. Potvin (eds), 13-15 May 2013, Perth, Australia, Australian Centre for Geomechanics, Perth, pp. 119-132.

Mercier-Langevin, F. and Hadjigeorgiou, J. (2011) Towards a better understanding of squeezing potential in hard rock mines, Mining Technology Journal, Vol. 120, No. 1, 2011, pp. 36-44.

Mercier-Langevin, F. and Turcotte, P. (2007) Evolution of ground support practices at Agnico Eagle's LaRonde Division: innovative solutions to high stress yielding ground, Rock Mechanics: Meeting Society's Challenges and Demands, in Proceedings 1st Canada-US Rock Mechanics Symposium, E. Eberhardt, D. Stead and T. Morrison (eds), 27-31 May 2007, Vancouver, Canada, Taylor \& Francis, pp. 1497-1504.

Mercier-Langevin, F. (2005) Projet de convergence des galeries - Phase 1: Consolidation de l'information disponible à la mine, Internal Memo, Agnico-Eagle Mines Ltd - LaRonde Division, Cadillac, Canada, 13 p.

Potvin, Y. and Hadjigeorgiou, J. (2008) Ground Support Strategies to Control Large Deformations in Mining Excavations, The Journal of the Southern African Institute of Mining and Metallurgy, Vol. 108, July 2008, pp. 393-400.

Sandy, M.P., Gibson, W. and Gaudreau, D. (2007) Canadian and Australian ground support practices in high deformation environments, in Proceedings Fourth International Seminar on Deep and High Stress Mining (Deep Mining 07), Y. Potvin (ed), 7-9 November 2007, Perth, Australia, Australian Centre for Geomechanics, Perth, pp. 297-312.

Simser, B.P. (2007) The weakest link - ground support observations at some Canadian shield hard rock mines, in Proceedings Fourth International Seminar on Deep and High Stress Mining (Deep Mining 07), Y. Potvin (ed), 7-9 November 2007, Perth, Australia, Australian Centre for Geomechanics, Perth, pp. 335-348.

Simser, B.P, Andrieux, P., Langevin, F., Parrott, T. and Turcotte, P. (2006) Field behaviour and failure modes of modified conebolts at the Craig, LaRonde and Brunswick mines in Canada, in Proceedings Third International Seminar on Deep and High Stress Mining Seminar, 2-4 October 2006, Quebec City, Canada, pp. 347-354.

Turcotte, P. (2010) Field behaviour of the hybrid bolt at LaRonde, in Proceedings Fifth International Seminar on Deep and High Stress Mining, M. Van Sint Jan and Y. Potvin (eds), 6-8 October 2010, Santiago, Chile, Australian Centre for Geomechanics, Perth, pp. 309-319. 
